\title{
Glutathione transferase activity and formation of macromolecular adducts in two cases of acute methyl bromide poisoning
}

\author{
Robert Garnier, Marie-Odile Rambourg-Schepens, Andreas Müller, Ernst Hallier
}

Centre Anti-poisons, Clinique

Toxicologique et Institut

Interuniversitaire de Médecine du Travail, Hôpital Fernand Widal, 200 rue du Faubourg Saint-Denis, 75010 Paris, France

R Garnier

Centre Anti-poisons, Hôpital Maison

Blanche, 51092 Reims cedex, France

M-O Rambourg-

Schepens

Institut für

Arbeitsphysiologie an der Universität

Dortmund,

Ardeystrasse 67

D-44139 Dortmund,

Germany

E Hallier

A Müller

Correspondence to:

Dr R Garnier, Centre

Dr Ramier, Centre

Anti-poisons, Clinique

Toxicologique et Ins

Interuniversitaire de

Médecine du Travail,

Hôpital Fernand Widal

200 rue du Faubourg

France.

Accepted 6 October 1995

\begin{abstract}
Objectives-To determine the activity of glutathione transferase and to measure the $S$-methylcysteine adducts in blood proteins, after acute inhalational exposure to methyl bromide. To examine the influence of the polymorphism of glutathione-S-transferase $\theta$ (GSTT1) on the neurotoxicity of methyl bromide.
\end{abstract}

Methods-Two workers acutely exposed to methyl bromide with inadequate respiratory protective devices were poisoned. Seven weeks after the accident, blood samples were drawn from both patients, for measurement of glutathione transferase activity in erythrocytes (conjugator status-that is, GSTT1 phenotype) and measurement of binding products of methyl bromide with blood proteins. Conjugator status was determined by a standard procedure. The binding product of methyl bromide, $S$-methylcysteine, was measured in globin and albumin.

Results-Duration and intensity of exposure were identical for both patients as they worked together with the same protective devices and with similar physical effort. However, one patient had very severe poisoning, whereas the other only developed mild neurotoxic symptoms. The first patient was a "conjugator" with normal glutathione transferase activity, whereas this activity was undetectable in the erythrocytes of the second patient, who consequently had higher concentrations of $\boldsymbol{S}$-methylcysteine adduct in albu$\min (149 v 91 \mathrm{nmol} / \mathrm{g}$ protein) and in globin ( $77 v 30 \mathrm{nmol} / \mathrm{g}$ protein).

Conclusions-Methyl bromide is genotoxic and neurotoxic. Its genotoxicity seems to be the consequence of the alkylating activity of the parent compound, and conjugation to glutathione has a protective effect. The data presented here suggest a different mechanism for methyl bromide neurotoxicity which could be related to the transformation of methylglutathione into toxic metabolites such as methanethiol and formaldehyde. If such metabolites are the ultimate toxic species, $\boldsymbol{N}$-acetylcysteine treatment could have a toxifying rather than a detoxifying effect.

(Occup Environ Med 1996;53:211-215)
Keywords: methyl bromide; poisoning; glutathione transferase

Methyl bromide has been used since the end of the 18th century. Up until the late 1950 s, it was mainly used as a fire extinguisher. Nowadays, it is primarily a fumigant for the control of nematodes, fungi, and weeds in greenhouses, as well as for the eradication of insects and rodents in mills, warehouses, grain elevators, ships, and freight cars.

Methyl bromide is a colourless gas; it is also odourless at concentrations up to several times the French maximum allowable concentration of $20 \mathrm{mg} / \mathrm{m}^{3}$. Therefore high exposure may occur unknowingly and several hundreds of cases of severe poisoning in humans have been reported. ${ }^{2}$

Short exposures to high concentrations may result in gastrointestinal, neurological, and respiratory symptoms. Early manifestations of methyl bromide poisoning include headache, nausea, vomiting, and dizziness; they may be preceded by a symptom-free interval of up to two hours. ${ }^{3}$ Progression of neurological symptoms to coma, myoclonus, generalised seizures, and distal axonopathy may follow. In such severe cases, lung damage is generally found: the most frequently reported lesion is pulmonary oedema. ${ }^{2}$ At this acute stage, hepatic or renal impairment may also be noted, but is usually mild. ${ }^{2}$ Status epilepticus (or status myoclonicus) is associated with a high mortality. ${ }^{4}$ In non-fatal cases, recovery is slow and neurological or psychiatric sequelae are frequent. ${ }^{2}$

Danse et $a l^{5}$ reported that methyl bromide was carcinogenic in Wistar rats, which developed squamous cell papillomas and carcinomas of the forestomach after oral doses. Other authors, however, showed regression of the forestomach lesions after discontinuation of exposure. ${ }^{6} \mathrm{~A}$ chronic inhalation study, also carried out in rats, did not show any carcinogenic activity of methyl bromide. ${ }^{7}$ Methyl bromide is a methylating agent which readily reacts with macromolecules. It was mutagenic in various procaryote and cellular systems ${ }^{1}$ and induced sister chromatid exchanges in human peripheral lymphocyte cultures. ${ }^{8}$

There are no reliable indicators of exposure to methyl bromide: methyl bromide is rapidly undetectable in human tissues, due to its short half life, ${ }^{39}$ concentrations of blood bromide 
and $S$-methylcysteine adduct are dependent on the metabolism of methyl bromide, which displays genetic polymorphism. ${ }^{10}$

Conjugation with glutathione to $S$-methylglutathione is the first step of the major metabolic pathway for all methyl halides in various rodent species. ${ }^{11} 13$ Conjugation of methyl bromide with glutathione is both non-enzymatic and catalysed by glutathione transferase in human erythrocytes. ${ }^{14}$ This enzyme activity shows polymorphism. ${ }^{10}$ Three quarters of the western European population are able to enzymatically conjugate methyl bromide with glutathione; the remaining quarter lacks this specific enzyme activity. ${ }^{15}$ It was shown that methyl bromide induced sister chromatid exchanges in vitro in the lymphocytes of nonconjugators, whereas such an effect was not found in the lymphocytes of conjugators. ${ }^{15}$ This indicates that the genotoxicity of methyl bromide is probably the consequence of the methylating activity of the parent compound and that conjugation to glutathione has a protective effect.

To date, the mechanism of methyl bromide neurotoxicity has not been elucidated. However, it is generally postulated that neurotoxic effects also result from direct alkylation of macromolecules; conjugation to glutathione is consequently thought to have a protective effect and giving $\mathrm{N}$-acetylcysteine is recommended by some authors to prevent the acute systemic effects of methyl bromide. ${ }^{16} \mathrm{We}$ report an accident involving two workers, in whom the clinical and laboratory features do not support these propositions.

\section{Patients and methods}

The first patient was admitted to the intensive care unit of the Reims Poison Centre about four hours after the end of exposure. The second patient was referred to the Occupational Health and Clinical Toxicology Department of Fernand-Widal Hospital, four days after the accident.

The circumstances of the accident were obtained through interviews with the second poisoned worker.

Both patients had repeated clinical examinations by internists and neurologists. Further investigations included: routine haematology, biochemical tests, standard urinalysis, chest radiography, electrocardiography, electroencephalography, neuropsychological tests, brainstem auditory, visual, and somatosensory evoked potentials, computed tomography and magnetic resonance imaging of the brain, electroneuromyography, and measurement of serum bromide concentrations.

Blood samples were drawn from both patients seven weeks after the accident for measurement of glutathione transferase activity in erythrocytes (conjugator status) and measurement of binding products of methyl bromide with blood proteins. Conjugator status was ascertained by the standard procedure for methyl bromide, according to Hallier et $a l .{ }^{15}$ The binding product of methyl bromide, $S$-methylcysteine, was measured in globin and albumin according to the method of Müller et al. ${ }^{17}$

\section{Results}

\section{CIRCUMSTANCES OF THE ACCIDENT}

The accident occurred in a nine floor mill. On day 1 , the two workers sealed all openings except one door at the bottom of the building; they placed methyl bromide cylinders on each floor; then both of them, wearing canister respirators, opened the cylinders; they started from the upper floors and immediately went out of the building at the end of the operation which lasted less than 10 minutes, and then sealed the escape door.

They returned on day 2 , about 24 hours after the beginning of fumigation. Protective clothing consisted of overalls, PVC gloves, working shoes and masks; as they thought the recommended airway protection was unnecessarily uncomfortable, they only wore face masks with disposable filters instead of the autonomous breathing apparatus which they should have used. At first, they removed seals and opened doors and windows on the ground floor. One of them then went up to the ninth floor and the other went to the eighth where they performed the same operation. They met at the seventh floor and then worked together, opening all windows on each floor, while going downstairs. The total operation lasted about 45 minutes. A sample of the atmosphere in the building had been taken at the very beginning of the ventilation procedure: the methyl bromide concentration was measured to be $17000 \mathrm{mg} / \mathrm{m}^{3}$.

\section{PATIENTS}

On their return to the ground floor both workers noted a chloroform like odour through their mask and experienced a slight burning sensation in the throat which prompted them to leave the building, remove their protecting devices and clothes, and take a shower. A few minutes after the end of exposure, both workers experienced nausea, vomiting, headache, and dizziness. Two hours later, one of them (patient 1) had severe myoclonic seizures. Both patients were soon admitted to the nearest rural hospital. Patient 1 received thiopental and flunitrazepam, and was intubated and mechanically ventilated. Both patients were then transferred to the intensive care unit of the Reims poison centre.

\section{Case 1}

Patient 1 was a previously healthy 43 year old man. On admission, he showed generalised seizures, cardiogenic shock, bilateral pulmonary oedema, profuse diarrhoea, and acute anuric renal failure. As well as standard supportive measures, treatment with intravenous $\mathrm{N}$-acetylcysteine was started five hours after the end of exposure: the initial dose of 140 $\mathrm{mg} / \mathrm{kg}$ was followed by $5 \mathrm{~g}$ doses every four hours until the fifth day. Diarrhoea resolved spontaneously within 24 hours. Pulmonary oedema was rapidly controlled by permanent 
positive pressure ventilation. The haemodynamic disturbances required high doses of catecholamines for five days. Because of the unstable haemodynamic condition, continuous haemofiltration was initially performed for 13 days, then haemodialysis was performed daily for another 21 days; renal function no longer required dialysis thereafter. Measurements of plasma bromide concentrations were performed on admission and on the next day. The initial bromide concentration was 156 $\mathrm{mg} / \mathrm{l}$ (normal range: $3.5-5.5 \mathrm{mg} / \mathrm{l}$ ) and returned to normal values on the second day, after 12 hours of haemofiltration. Surprisingly, liver function tests remained normal throughout the acute phase of poisoning. Necrotic lesions of the skin appeared on the distal extremities of the fingers and toes in the first seven days after admission; moist dressings allowed complete healing within two weeks. The tonic clonic generalised convulsions were only partially controlled by repeated intravenous doses of clonazepam and thiopental; a few days after admission, they turned into generalised myoclonic jerks which required curarisation with pancuronium until the 21 st day. Suppression of myoclonic activity was then achieved by long term treatment with carbamazepine and clonazepam. Mechanical ventilation was stopped on the 22nd day, but owing to absent gag reflex, the patient was finally extubated only on the 33rd day. He was discharged from the intensive care unit to a physical rehabilitation centre on the 52nd day. He still had ataxia and debilitating action/intention myoclonus, bilateral cortical deafness, and mental deterioration. One year later, his situation is unchanged and he is confined to a wheelchair.

\section{Case 2}

On admission, the second worker (patient 2) had only mild symptoms (nausea, headache, dizziness, epigastric pain) which persisted for two days. He did not develop seizures or myoclonus. The serum bromide concentration measured on the second day was $46.6 \mathrm{mg} / \mathrm{l}$. No further investigations were performed during the first three days and this patient was finally referred to the Department of Occupational Health and Clinical Toxicology of Fernand-Widal hospital, four days after the accident. The medical history of this 39 year old man was unremarkable. He was not taking any medication. He was a non-smoker and drank less than $40 \mathrm{~g}$ of alcohol daily. Four days after the accident, he complained of headache, insomnia, weakness, and memory difficulties. Physical examination was unremarkable except for a bilaterally diminished ankle jerk reflex. Routine laboratory tests including blood cell count, serum biochemistry (glucose, urea nitrogen, creatinine, sodium, potassium, chloride, bicarbonate, serum aspartate aminotransferase, and serum alanine aminotransferase, $\gamma$-glutamyltranspeptidase, and alkaline phosphatase), urinary glucose and urinary protein, chest $x$ ray, and an electrocardiogram showed no abnormalities.
Conjugator status and S-methylcysteine adducts in albumin and globin from blood samples of the two patients

\begin{tabular}{llcl}
\hline & & \multicolumn{2}{l}{$\begin{array}{l}\text { S-methylcysteine adducts } \\
\text { (nmol/g protein) }\end{array}$} \\
\cline { 3 - 4 } Patient & Conjugator status & Albumin & Globin \\
\hline 1 & Conjugator & 91 & 30 \\
2 & Non-conjugator & 149 & 77 \\
\hline
\end{tabular}

Serum bromide concentration was below the limit of detection. Neuropsychological tests were performed and showed impaired performance on memory tasks, especially those exploring immediate and verbal memory. Manual dexterity and reaction time were also impaired. Electroencephalography was normal. Interpeak latency I-V of brainstem auditory evoked potentials was bilaterally increased. Somatosensory and visual evoked potentials were normal. Electroneuromyography confirmed the mild distal motor neuropathy. On follow up, progressive recovery was reported by the patient and confirmed by tests: the distal motor neuropathy disappeared within six months, latencies of brainstem auditory evoked potentials returned to normal within 12 months. Neuropsychological tests also progressively improved: one year after the accident, they only showed a mild defect of verbal memory.

DETERMINATION OF CONJUGATOR STATUS Measurement of binding products of methyl bromide with blood proteins

The table shows the results of these investigations. The first patient was a conjugator, and the second was a non-conjugator. $S$ Methylcysteine adducts were high in both albumin and globin and were higher in the second patient who was a non-conjugator.

\section{Discussion}

Conjugation with glutathione is the first step in the main metabolic pathway of monohalomethanes. ${ }^{141819}$ Methylglutathione is then transformed into $S$-methylcysteine by transpeptidases. Further metabolism produces methanethiol through methylthioacetic acid. Oxidation of methanethiol generates formaldehyde and hydrogen sulphide which may be further oxidised into formate and sulphate respectively. ${ }^{11}$

Whether methyl bromide toxicity is due to direct alkylation of cellular components (primarily glutathione, then macromolecules) by the parent compound, or can be attributed to toxic metabolites such as methanethiol and formaldehyde has been extensively disputed for the past 10 years. Exposure to methyl bromide has induced glutathione depletion in various systems. ${ }^{1120-22}$ However, the significance of this finding is unclear, as shown by the conflicting results of experimental studies. On the one hand, glutathione depletion was found to increase methyl bromide toxicity in rats ${ }^{21}$ and pretreatment of mice, rats, or rabbits with glutathione, cysteine, $\mathrm{N}$-acetylcysteine, or methionine had a protective effect, ${ }^{23}{ }^{24}$ on the 
other hand, glutathione depletion before exposure inhibited toxicity of another monohalomethane, methyl chloride, in mice. ${ }^{25}$ These conflicting results may be explained by significant differences between species in the metabolism of monohalomethanes; such differences have been shown to exist-for example, glutathione transferase activity varies considerably from one species to another. ${ }^{18}$ Methodological bias may be another explanation for these discrepancies: the doses and conditions of exposure varied considerably in the published studies.

Some clarification of the mechanism of methyl bromide toxicity was gained recently, when Hallier et $a l^{15}$ showed that in vitro conjugation with glutathione protected human lymphocytes from the induction of sister chromatid exchanges caused by this halomethane. This indicates that the genotoxic effects are probably due to the parent compound.

The data presented here suggest a different mechanism for methyl bromide neurotoxicity. Indeed, these two workers experienced the same exposure to the fumigant for an identical duration and intensity, as they worked together and used the same protective devices. As they produced very similar physical efforts, it is highly probable that they absorbed amounts of methyl bromide which were not significantly different. However, one of them (patient 1) had very severe poisoning, whereas the other (patient 2) developed only mildly neurotoxic symptoms.

Glutathione transferase activity was measured in erythrocytes of both patients. The first patient was a conjugator: he possessed this specific enzyme activity, which was lacking in the erythrocytes of the second patient (a so called non-conjugator). The glutathione transferase responsible for the metabolism of methyl bromide belongs to class $\theta$. It has been characterised by Schröder et al. ${ }^{10}$ The polymorphism of glutathione transferase activity is not restricted to erythrocytes. It was recently shown that it is genetically determined. ${ }^{26}$ Conjugators are either homozygous or heterozygous bearers of the gene, whereas nonconjugators have a homozygous null genotype. There is a wide variation in the prevalence of the null genotype in different ethnic groups: In a recent study, $20.4 \%$ of whites, $21.8 \%$ of African-Americans, $64.6 \%$ of Chinese, $60.2 \%$ of Koreans, and $\mathbf{9 \cdot 7 \%}$ of Mexican-Americans lacked this gene. ${ }^{27}$

In non-conjugators, formation of $S$-methylglutathione is always very low, as it is limited to the non-enzymatic reaction of methyl bromide with glutathione. This implies that, for the same exposure, non-conjugators receive a higher internal dose of the parent compound. Methyl bromide is a highly reactive molecule which can methylate cellular components. Non-conjugators are therefore expected to have a higher level of alkylated proteins. Indeed, we found more $S$-methylcysteine adducts in globin and serum albumin of the second patient who was a non-conjugator. It should be emphasised that the concentrations of adduct measured in both patients were very high, as blood samples were drawn seven weeks after exposure (table). The half lives of albumin and globin adducts are seven to 10 days and about two months, respectively. The normal concentrations of $S$-methylcysteine adduct for people not exposed to methyl bromide are about $15 \mathrm{nmol} / \mathrm{g}$ (range: 13 to 18 ) in both albumin and globin (14.8 (1.9) in albumin and $14.5(2.5)$ in globin). ${ }^{16}$ In field studies, soil fumigators had $26.6(11.8) \mathrm{nmol} / \mathrm{g}$ of $S$-methylcysteine adducts in globin and $38 \cdot 1$ $(31.4) \mathrm{nmol} / \mathrm{g}$ in albumin. Some people performing specific tasks with a high risk of exposure to methyl bromide had higher concentrations: up to $65 \mathrm{nmol} / \mathrm{g}$ in globin and $140 \mathrm{nmol} / \mathrm{g}$ in albumin. The concentrations of adduct were higher for space fumigators than for soil fumigators: $32.9(14.6) \mathrm{nmol} / \mathrm{g}$ in globin and $74.3(38 \cdot 7) \mathrm{nmol} / \mathrm{g}$ in albumin. All these values were obtained from workers whose blood was analysed immediately after exposure to methyl bromide. ${ }^{1728}$

After exposure of whole blood to methyl bromide in vitro, non-conjugators have higher concentrations of $S$-methylcysteine adduct in proteins and also more sister chromatid exchanges in lymphocytes than conjugators. ${ }^{15}$ Patient 2, who was a non-conjugator, had higher concentrations of adduct but fewer neurotoxic effects than patient 1 . This suggests that methylation of cellular components is not the mechanism of methyl bromide neurotoxicity and provides support for the hypothesis that the neurotoxic effects of monohalomethanes are related to their conjugation with glutathione, $S$-methylglutathione, or some of its subsequent metabolites being responsible for the symptoms found after acute exposure. Previous studies have suggested that methanethiol and formaldehyde may be the ultimate toxic metabolites. ${ }^{1125}$ The toxic effects of methanethiol are probably due to its rapid transformation into formaldehyde and hydrogen sulphide. ${ }^{29}{ }^{30}$ Formaldehyde is a highly reactive compound. Hydrogen sulphide is a strong inhibitor of cytochrome oxidase. ${ }^{31}$

If the initial conjugation of methyl bromide with glutathione has a toxifying rather than a detoxifying effect, treatment with $\mathrm{N}$-acetylcysteine, which has been proposed by some authors, ${ }^{16}$ should be questioned. $N$ Acetylcysteine is a precursor of glutathione. Indeed, if metabolites of $S$-methylglutathione are the ultimate toxic species, to give $\mathrm{N}$-acetylcysteine could have both a toxifying and a detoxifying effect: it would increase the production of methanethiol and formaldehyde but would also accelerate neutralisation of formaldehyde, ${ }^{32}$ which is one of the two probable ultimate toxic metabolites. Consequently, to give glutathione precursors could either increase or decrease methyl bromide neurotoxicity depending upon the conditions of exposure and the therapeutic protocol. Patient 1 , who was a conjugator, received $N$-acetylcysteine, but this treatment did not have any obvious protective effect. From a practical point of view, the consequences of $N$-acetylcysteine being given to cases with methyl bromide poisoning should certainly be further investigated before it can be recommended as specific treatment. 
1 International Agency for Research on Cancer IARC. Monographs on the evaluation of the carcinogenic risk of chemicals to humans. Vol 41-Some halogenated hydrocarbons and pesticide exposures. Lyon: 1986:187-212.

2 Alexeef BV, Kilgore WW. Methyl bromide. Residue Reviews 1983;88:101-53.

3 Hustinx WNM, Van de Laar RTH, Van Huffelen AC, Verwey JC, Meulenbelt J, Savelkoul TJF. Systemic effects of inhalational methyl bromide poisoning: a study of nine cases occupationally exposed due to inadvertent spread during fumigation. $\mathrm{Br} \mathcal{F}$ Ind Med 1993;50:155-9.

4 Mellerio F, Levy-Alcover MA. Myoclonies d'origine toxique. Revue d'Electroencéphalographie et de Neurophysiologie Clinique 1982;12:210-8.

5 Danse LHJC, Van Velsen FL, Van der Heijden CA. Methyl bromide: carcinogenic effects in the rat fore-stomach. Toxicol Appl Pharmacol 1984;72:262-71.

6 Boorman GA, Hong HL, Jameson CW, Yoshitomi K, Maronpot RR. Regression of methyl bromide-induced Maronpot RR. Regression of methyl bromide-induced forestomach lesior

7 Reuzel PGJ, Dreef-Van der Meulen HC, Hollanders VMH, Kuper CF, Feron VJ, Van der Heijden CA. Chronic inhalation toxicity and carcinogenicity study of methyl bromide in Wistar rats. Fd Chem Toxicol 1991;29:31-9.

8 Tucker JD, Xu J, Stewart J, Baciu PC, Ong T. Detection of sister chromatid exchanges induced by volatile genotoxicants. Teratogenesis Carcinog Mutagen 1986;6:15-21.

9 IPCS. Environmental health criteria 166. Methyl bromide. Geneva: World Health Organization, 1995.

10 Schröder KR, Hallier E, Peter H, Bolt HM. Dissociation of a new glutathione S-transferase activity in human erya new glutathione S-transferase activity in hum
throcytes. Biochem Pharmacol 1992;43:1671-4.

11 Kornbrust KS, Bus JS. The role of glutathione and cytochrome P-450 in the metabolism of methyl chloride. Toxicol Appl Pharmacol 1983;67:246-56.

12 Barnsley EA, Young L. Biochemical studies of toxic agents: the metabolism of iodomethane. Biochem $\mathcal{f}$ 1965;95: $77-81$.

13 Johnson MK. Studies on glutathione $S$-alkyltransferase in the rat. Biochem 7 1966;98:44-56.

14 Hallier E, Deutschmann S, Reichel C, Bolt HM, Peter H. A comparative investigation of the metabolism of methyl bromide and methyl iodide in human erythrocytes. Int Arch Occup Environ Health 1990;62:221-5.

15 Hallier E, Langhof T, Dannapel D, Leutbecher $M$, Schröder K, Goergens HW, et al . Polymorphism of glutathione conjugation of methyl bromide, ethylene oxide and dichloromethane in human blood: influence on the induction of sister chromatid exchanges (SCE) in lymphocytes. Arch Toxicol 1993;67:173-8.

$16 \mathrm{Zwaveling} \mathrm{JH,} \mathrm{de} \mathrm{Kort} \mathrm{WLAH,} \mathrm{Meulenbelt} \mathrm{J,} \mathrm{Hezemans-}$ angster B. Exposure of the skin to methyl bromide: a study of six cases occupationally exposed to high concent
17 Müller AMF, Hallier E, Westphal G, Schröder KR, Bolt HM. Determination of methylated globin and albumin for biomonitoring of exposure to methylating agents using HPLC with precolumn fluorescent derivatization. Fresenius $\mathcal{F}$ Anal Chem 1994;350:712-5.

Fresenius $\mathcal{f}$ Anal Chem 1994;350:712-5.
18 Peter H, Deutschmann S, Reichel C, Hallier E. Metabolism of methyl chloride by human erythrocytes. Arch Toxicol 1989;63:351-5.

19 Bonnefoi MS, Davenport CJ, Morgan KT. Metabolism and toxicity of methyl iodide in primary dissociated neural cell cultures. Neurotoxicology 1991;12:33-46.

20 Alexeef GV, Kilgore WW, Munoz P, Watt D. Determination of acute toxic effects in mice following exposure to methyl bromide. I Toxicol Environ Health 1985;15: 109-23.

21 Thomas DA, Lacy SA, Morgan KT. Studies on the mechanisms of methyl bromide-induced olfactory toxicity. Toxicologist 1989;9:37.

22 Davenport CJ, Ali SF, Miller FJ, Lipe GW, Morgan KT, Bonnefoi MS. Effect of methyl bromide on regional brain
glutathione, glutathione- $S$-transferases, monoamines, glutathione, glutathione-S-transferases, monoamines,
and amino acids in F 344 rats. Toxicol Appl Pharmacol and amino acids

23 Mizynkova IG, Bakhishev GN. Specific treatment of acute poisoning with methyl bromide. Vrach Delo 1971;7: 128-31.

24 Hashimoto Y, Nagao N, Ishizu S. The effect of GSH as an antidote for $\mathrm{MeBr}$ poisoning in mice. Ludwigshafen: Medichem, 1986:494-7.

25 Chellman GJ, White RD, Norton RM, Bus JS. Inhibition of the acute toxicity of methyl chloride in male B6C3F1 mice by glutathione depletion. Toxicol Appl Pharmacol mice by glutathion

26 Pemble S, Schröder KR, Spencer SR, Meyer DJ, Hallier E, Bolt HM, et al. Human glutathione $S$-transferase theta (GSTT1): cDNA cloning and the characterization of a genetic polymorphism. Biochem $\mathcal{f}$ 1994;300:271-6.

27 Nelson HH, Wiencke JK, Christiani DC, Cheng TJ, ZhengFa Z, Schwartz BS, et al. Ethnic differences in the prevalence of the homozygous deleted genotype of glutathione $S$-transferase theta. Carcinogenesis 1995;16:1243-5.

28 Goergens HW, Hallier E, Müller A, Bolt HM Macromolecular adducts in the use of methyl bromide as fumigant. Toxicol Lett 1994;72:199-203.

29 Blom HJ, Tangerman A. Methanethiol metabolism in whole blood. f Lab Clin Med 1988;111:606-10.

30 Waller RL. Methanethiol inhibition of mitochondrial respiration. Toxicol Appl Pharmacol 1977;42:111-7.

31 Nicholls P. The effect of sulphide on cytochrome $a_{3}$, isosteric and allosteric shifts of the reduced alpha peak. Biochim Biophys Acta 1975;396:24-35.

32 Casanova M, d'Heck AH. Further studies of the metabolic incorporation and covalent binding of inhaled $\left({ }^{3} \mathrm{H}\right)$ and ${ }^{\left({ }^{4} \mathrm{C}\right)}$ formaldehyde in Fischer 344 rats: effects of glutathione depletion. Toxicol Appl Pharmacol 1987;89: 105-21. 